\section{Third Ventricle Cyst: A Difficult Diagnosis}

SIR: Upadhyaya \& Sud (Journal, April 1988, 152, 567-569) reported difficulties in diagnosing third ventricle cysts. We describe another patient whose psychological and physical symptoms were hard to tie together.

Case report: Mrs A. was a successful professional Jewish woman in her 40 s with an underachieving unhappy husband and four children. Ten years ago the family tried family therapy and EST, prompted by the second child's behavioural problems. Eighteen months ago Mrs A. became exhausted and forgetful, and moved to a less demanding job. As she was post-menopausal, with hot flushes and sweating, her GP referred her to the menopause clinic where she received a hormonal implant, with little effect. Through a medical friend, she sought a physician's opinion privately. She now also complained of waking early, a weight gain of $12 \mathrm{~kg}$, breathlessness on effort, and "dragging feet towards the end of the day". Physical examination, as well as metabolic and endocrine blood tests and respiratory function tests, were normal. The physician diagnosed primary depression and referred her non-urgently to psychiatrist $I$, who was sent her notes.

Meanwhile Mr A. took a large overdose. The medical friend involved psychiatrist II, who admitted $\mathrm{Mr} \mathrm{A}$. under psychiatrist III. Mrs A. felt desperate and suicidal and was referred by psychiatrist II to psychiatrist IV for emergency psychiatric assessment. Psychiatrist IV arranged admission under psychiatrist $\mathrm{V}$ on our psychosomatic ward.

On admission Mrs A. seemed to give a full history but forgot to mention her shuffling and recent headaches. This information could only later be obtained, as psychiatrist I still had the medical notes and Mr A. was too distressed to be interviewed. Mrs A. was tearful and depressed. Bedside cognitive testing was normal. There were no abnormal physical signs.

Psychiatrist III's team felt that family treatment was urgently needed and proposed a total system review including all those involved with the couple. At the time a major disaster was draining resources away from our ward. We did not know Mrs A. well enough to be confident about starting the system review, and decided to assess her further in her own right, taking stock of information already gathered. We wanted to wait for any psychological benefits of her recent high-dose hormone implant. We hoped that her complaint of poor memory would resolve with lifting depression and postponed psychometric testing.

Away from her family Mrs A.'s mood improved, but there were still sufficient depressive features to justify imipramine treatment. Over the next month her mood improved; instead, she emphasised her memory problems and her shuffling which she had first noticed on a visit to Jerusalem 15 months before. Bedside cognitive testing remained normal, but Mrs A. repeatedly forgot appointments and names. Full psychometric assessment revealed an IQ of 106 and marked discrepancy between verbal and performance scales. On repeat physical examination Mrs A. was ataxic and had early bilateral papilloedema with a flame haemorrhage. A CT scan demonstrated a third ventricle cyst. Rapid deterioration followed, so dexamethasone was started before the cyst was excised. She made a good post-operative recovery and 3 months later her performance on psychometric testing showed above-average intelligence $(\mathrm{IQ}=131)$ and short-term memory.

Different doctors had interpreted Mrs A.'s story as a clear-cut case of a depressed menopausal woman in family crisis. Organic illness had been excluded. The many contaminating factors from Mrs $A$. and her family and also within our own system impeded our diagnostic process considerably. We too initially failed to recognise the symptoms of slowly developing hydrocephalus, despite all early pointers. Only once we had assimilated all the information on Mrs A. and observed her further deterioration did we pick up the extremely rare third ventricle cyst.

R. L. RAMSEY

U. H. SCHMIDT

R. M. ROSSER

\section{Middlesex Hospital}

London WIN 8AA

\section{Naloxone treatment for opiate withdrawal syndrome}

SIR: In an open-trial study with five patients, Vlissides et al (Journal, April 1988, 152, 565-567) could not reproduce Hendrie's (1985) experimental findings, that the abstinence syndrome in opiate addiction is attenuated by naloxone. All patients experienced severe withdrawal syndromes within minutes after intravenous administration of an unspecified dose of naloxone.

We have treated 12 opiate addicts (2-10 year's addiction history, satisfying DSM-III-R criteria) for detoxification by an acute intravenous administration of a single dose of naloxone $(10 \mathrm{mg})$ during a short (30-60 min) general anesthesia followed by continuous administration of $0.8 \mathrm{mg} / \mathrm{h}$ naloxone for a further 24 hours. After awaking from anesthesia, all patients showed no or only mild withdrawal signs, although naloxone treatment was continued. Six of these patients were then treated further with single doses ( $0.4 \mathrm{mg}$ naloxone) every two hours for an additional 24 hours. In contrast, the other patients were treated with $0.4 \mathrm{mg} / \mathrm{h}$ naloxone intravenously as long as their urine was found opiate positive (approximately 72 hours). Opiate excretion in urine was monitored in all patients by EMIT-dau test. The urines of the patients were found to be opiatepositive for approximately 72-96 hours after the last opiate intake. In the first group, mild withdrawal signs (goose flesh, stomach pain, insomnia) were seen only after naloxone treatment had been discontinued, and could be still observed as long as the urine 